\title{
Effect of electro acupuncture versus low level laser therapy on lipid profile in obesity
}

Rabab A. Mohamed*, Abeer M. Yousef and Hanaa K. Ata

*Correspondence: rabab_ali1978@hotmail.com

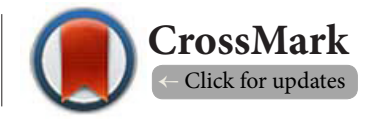

Basic Science Department, Faculty of Physical Therapy, Cairo University, Giza, Egypt.

\begin{abstract}
Background: Obesity is becoming increasingly common in the general population and is associated with several other conditions such as hypertension, diabetes, dyslipidemia, and cardiovascular disease. Abnormal blood lipids have been firmly established as a modifiable risk factor for the development of cardiovascular disease. However, medical practice in the area of lipid management is highly variable and has not been aggressively pursued for large number of patients that may be at risk.

Purpose: This study aimed to find out the effectiveness of electro acupuncture versus low level laser therapy on lipid profile in obesity.

Methods: Forty five patients including both male and female with mean age 39.93土3.47 and BMI $37.98 \pm 1.24$ were enrolled in the study and divided randomly in to three groups. Group A had received LLLT $\left(632.8 \mathrm{~nm}-16 \mathrm{~J} / \mathrm{cm}^{2}\right)$ and aerobic exercises. Group B had received electro acupuncture andaerobic exercises. Group C had received aerobic exercises only. Blood samples were taken from each patient for analysis before initiation of the program and after completion of study.

Results: Study showed significant improvement in three groups after the treatment but in comparison electro acupuncture group showed significant results with respect to low level laser therapy group and control group.

Conclusion: Significant difference was found between electro acupuncture and low level laser therapy approaches in treating obesity. Findings of this study revealed the fact that treatment sessions of electro acupuncture were superior to low level laser therapy group in terms ofsignificant improvement in cholesterol, LDL, HDL and TG levels in patients with obesity.
\end{abstract}

Keywords: Electro Acupuncture, Low Level Laser Therapy, Lipid Profile, Obesity

\section{Introduction}

Obesity represents one of the most serious global health issues. The prevalence of obesity has increased at an alarming rate over the past 2 decades to the extent that it could be considered a pandemic. Over 3000 Million adults worldwide are obese [1]. Obesity is a determinant factor in the development of cardiovascular diseases (CV), and is associated to an increased incidence of hypertension, diabetes, metabolic syndrome and cardiac target organ damage [2].

Elevated triglyceride levels, small low density lipoproteins (LDL) particles, and diabetes in women and men were also strongly associated with higher BMI values in women and men. Also it was found that increased BMI is associated with an adverse effect on increasing risk of coronary heart diseases (CHD). These results emphasize the importance of excess body fat as a public health issue [3].

Abnormal blood lipids have been firmly established as a modifiable risk factor for the development of CV disease. However medical practice in the area of lipid management is highly variable and has not been aggressively pursued for large number of patients that may be at risk [4].

Lipid profile (Lipid test, cholesterol test, lipoprotein profile) is 
used to diagnose a lipid disorder. It is a detailed blood test for cholesterol. The subject should to be fast for $9-12$ hours prior to the test. Routinely performed on plasma include measurement of total cholesterol (TC), triglyceride (TG), high density lipoproteins (HDL), and LDL [5]. Due to the "hidden" nature of abnormal lipid profiles, hypercholesterolemia is referred to as the "silent killer" as individuals frequently overlook the need to have regular cholesterol tests [6].

There are several different modalities for treatment of obesity one of which is acupuncture. It would be desirable to control obesity by safe and effective treatment modalities, and among the different methods acupuncture is one of the most popular complementary treatments. Acupuncture is performed by stimulating particular points on the skin called acupoints. Among several methods used for acupoints stimulation [7], needling is one of the most common methods, and stimulation can either be manual or electrical (electro acupuncture). Acupuncture has been used in the treatment of several diseases including obesity $[\mathbf{8 , 9}]$ and also immunerelated diseases, such as allergic disorders, autoimmune diseases, and immunodeficiency-syndromes [10,11].

Low-level laser therapy (LLLT) has evolved as an efficient tool to provide therapeutic outcomes for a variety of medical indications. Recent studies on LLLT indicate "liquefaction" or release of stored fat in adiposities by opening of the cell membrane after a short treatment. Fat cells that were not exposed to the laser treatment looked like round grapes. Eighty percent of the fat was released from the fat cells after $4 \mathrm{~min}$ of laser light exposure and 99\% was released after 6 min of exposure. After exposure to the laser light, pores in fat cells were visible by scanning electron microscope. It was presumed, but not demonstrated, that the fat was released from these pores, taken up in the lymphatic and reesterified in other tissues or metabolized for energy [12]. Exercise is extremely important throughout a men's lifetime particularly as he gets older. Regular exercise benefits the heart and bones, regulate weight, contribute to sense of overall well-being and improves mood. If man is physically inactive, he is more subjected to CHD, obesity, high blood pressure, diabetes and osteoporosis [13].

There is little published research regarding which tools can be used with confidence. This research is designed to provide researchers and clinicians with a guide to the current and emerging management tools specifically associated with visceral obesity research and practice.

Therefore, the research questions for this study were:

Is there a significant effect of low level laser therapy (LLLT) on lipid profile in obesity? Is there a significant effect of Electro Acupuncture lipid profile in obesity? Is there a significant difference between effect of (LLLT) and Electro Acupuncture on lipid profile in obesity?

\section{Materials and methods Subjects}

Forty five patients of both gender ( 34 females, 16 males) had high lipid profile value (LDL Low Density Lipoprotein from 130 to $160 \mathrm{mg} / \mathrm{dl}$-HDL High Density Lipoprotein from 30 to $40 \mathrm{mg} /$ dL-TG Triglycerides from 150 to $250 \mathrm{mg} / \mathrm{dL}$-TC Total cholesterol from 200 to $300 \mathrm{mg} / \mathrm{dL}$ ) participated in this study, their ages ranged from 35 to 45 years. All patients with moderate obesity mean (BMI ranged from 35 to $39.9 \mathrm{~kg} / \mathrm{m}^{2}$ ). They were recruited from new Qasr El Ainy teaching hospital outpatient clinics. All participants signed an informed consent prior to the study. Patients with a history of photosensitivity, Alcohol abuse and smokers, Hypothyroidism, lymphatic obstruction and Patient suffering from any uncontrolled conditions (sever hypertension, renal failure, unstable angina, diabetes mellitus, myocardial infarction, cardiovascular instability and severe autonomic neuropathy) which may affect treatment progressions were excluded from the study. Patients were randomly assigned into three groups with fifteen patients in each group, Group A, patients in this group received low level laser therapy $\left(632.8 \mathrm{~nm}-16 \mathrm{~J} / \mathrm{cm}^{2}\right)$, aerobic exercises (walking on treadmill for $30 \mathrm{~min}$ ) twice weekly for 8 weeks. Group B, patients in this group received electro acupuncture, aerobic training (walking on treadmill for $30 \mathrm{~min}$ ) twice weekly for 8 weeks. Group C, patients in this group received aerobic exercises only (walking on treadmill for $30 \mathrm{~min}$ ) twice weekly for 8 weeks. The randomization was done by a colleague independent and blindedto the study who took a sealed opaque envelope from a box following a numerical sequence; within which the group description was randomly placed within them.

\section{Instrumentation}

\section{A) Measurement instrumentation \\ 1- Laboratory Investigation \\ 1. Measurement of fasting serum lipid profile Blood sample}

A three milliliter-sample of venous blood had been drawn from the antecubital vein after 12-14 hours fast from all patients before the initiation of the program and after the completion of the study (i.e. at the end of the 8th week) to be assessed for measurement of fasting serum lipid profile (TC,TG,HDL,LDL) [14].

\section{2- Standard Weight Scale (SWS)}

Standard weight scale was used to measure the weight in kilogram and height in meter for all male patients before starting treatment. In the most widely used classification of body mass, body weight is expressed in terms of body mass index (BMI).

\section{B) Treatment Instrumentation 1-Lapex 2000 BCS lipolaser}

The Lapex 2000 BCS (LipoLaser) is a 100\% Non-invasive, laserbased, spot fat reduction and body contouring system. Offering the relaxation of a 40-minute massage with the benefits of inch loss without a painful incision, the Lapex 2000 BCS (LipoLaser) uses laser energy to safely (and painlessly) pen- 

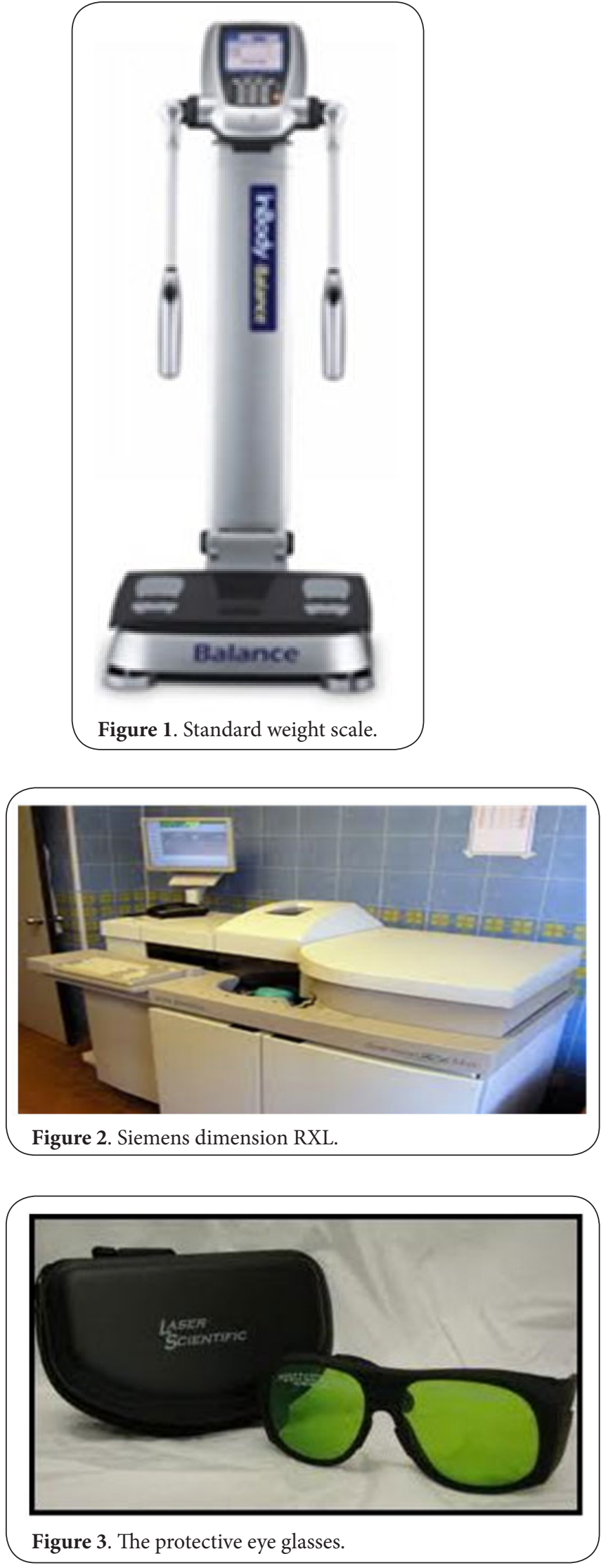

etrate the skin and target specific adipose (or fat cells) [12].

\section{2- Protective Eye Glasses}

These protective eye glasses were worn during application of laser to avoid permanent eye damage resulting from direct exposure to the beam [15].

\section{3- Electro Acupuncture}

An electrical stimulator was used with an output of programmed pulse voltage, $30-40 \mathrm{~Hz}$, dense-disperse wave, $390 \mu \mathrm{S}$ square pulse, and at a maximal tolerable intensity, $500 \Omega$ (12$23 \mathrm{~V}$ ) (a strong but not painful sensation to the patient). Each acupuncture treatment lasted for 20 minutes. All subjects were asked to receive two treatment sessions per week for a total of 8 weeks [16].

\section{4-Treadmill}

All patients in the study attended to the program of walking 30 minutes on treadmill 2 times per week for 8 weeks according to the following parameters;-

Warm up: The warm up phase started with walking on a treadmill at a speed of $4-5 \mathrm{~km} / \mathrm{h}$ with $0 \%$ grade elevation for 5 min.

Exercise: walking on treadmill 20 minutes at (60-75) \% of the heart rate reserve (HRR). The treadmill speedand inclination were increased gradually, and adjusted for each subject according to her/his intensity based on the target heart rate. Karvonen equation: [(maximum heart rate-resting heartrate . $\%$ intensity) + resting heart rate]. A polar heart rate monitor was used to monitor the heartrate every 5 min during exercise. If the target heart rate exceeded the calculated one, the treadmill speed was slowed down until heart rate adjustment took place.

Cool down: The warm up phase started with walking on a treadmill at a speed of $4-5 \mathrm{~km} / \mathrm{h}$ with $0 \%$ grade elevation for $5 \min [17]$.

\section{Treatment procedures}

\section{-Patient preparation for all groups}

The purpose of the study was explained by researcher to each participant.

All patients were instructed not to eat before the test by 12 hours for lipid profile testing. Each participant would sign written approval Consent form. The patients were instructed not to eat heavy meal for two hours before training. The laboratory investigations were performed before the beginning of the program and after completion of the study (after the end of 8th week).

\section{Procedures of electro acupuncture}

Eight acupuncture points on the abdomen, including Tianshu (ST-25) both sides, Weidao (GB-28) both sides, Zhongwan (REN-12) Shuifen (REN-9) Guanyuan (REN-4) Sanyinjiao (SP-6), acupuncture needling with manipulation and use the normal 
electric lines of the electric acupuncture machine (Ying Lee, KWD 808) to 4 needles on the abdomen, two needles (ST-25) and (GB-28) on each side, was applied for 20 minutes. The needles were connected to an electrical stimulator. Electricity was generated as an output of programmed pulse voltage, $30-40 \mathrm{~Hz}$, dense-disperse wave, $390 \mu \mathrm{S}$ square pulse, and at a maximal tolerable intensity, $500 \Omega(12-23 \mathrm{~V}$ ) (a strong but not painful sensation to the patient). Each acupuncture treatment lasted for 20 minutes. All subjects were asked to receive two treatment sessions per week for a total of 8weeks [16].

\section{Procedures of Lapex 2000BCS laser application}

Each patient was placed into a comfortable supine lying position. The therapist position strides standing beside patient for observation any problems. Both the patient and the therapist wore protective eye glasses. Two smaller probes lasers were placed over the appropriate lymphatic glands and hold in place. The Lapex BCS lipolaser was switched on for 10 minutes, then was re-located and was turned on for other 10 minutes; this was repeated until all the spot fatty areas were treated, usually in $\mathbf{4 0}$ minutes.

In order to increase the body's ability to remove the triglycerides (the broken down fat cells) it will be necessary to assist this natural process by increasing the metabolic rate. This can be achieved in a number of ways but they all involve some form of exercise. The use of a whole body vibration plate machine for about 10 minutes is effective right after the treatment. The treatment was applied twice per week for 2 months [12].

\section{Statistical analysis}

Data were analyzed using the SPSS computer program, ver- sion 16.0. Means and standard deviation (SD) of all studied parameters were calculated separately. Threshold for statistical significance was set as $p<=0.05$. Kolmogorov-smirnov test was used, that reflect the data was normally distributed, so parametric statistical tests in the form of Multivariate Analysis of Variance (MANOVA) test was used to study significance difference between pre and post treatment results among three groups (A, B and C).

\section{Results \\ General Characteristics of the Subjects Total cholesterol}

MANOVA test revealed that there were no statistical significant differences between the three groups for the pretreatment. While post treatment there were statistical significant differences between the three groups mean values as shown in Tables $\mathbf{1}$ and $\mathbf{2}$.

\section{Low density lipoprotein}

MANOVA test revealed that there were no statistical significant differences between the three groups for the pretreatment. While post treatment there were statistical significant differences between the three groups mean values as shown in Table 3.

\section{High density lipoprotein}

MANOVA test revealed that there were no statistical significant differences between the three groups for the pretreatment. While post treatment there were statistical significant differences between the three groups mean values as shown in Table 4 .

Triglyceride

MANOVA test revealed that there were no statistical significant

Table 1. General characteristics of subjects in the study groups.

\begin{tabular}{llllll}
\hline General characteristics & Group A & Group B & Group C & F-value & P-value \\
\hline Age $(\mathrm{yrs})$ & $39.53 \pm 2.82$ & $39.93 \pm 3.47$ & $39.26 \pm 2.96$ & 0.176 & $0.839^{\star}$ \\
Weight $(\mathrm{kg})$ & $95.33 \pm 4.98$ & $94.2 \pm 6.81$ & $93.46 \pm 6.57$ & 0.288 & $0.571^{\star}$ \\
Height $(\mathrm{cm})$ & $168.66 \pm 2.79$ & $167.93 \pm 3.34$ & $168.4 \pm 2.87$ & 2.879 & $0.067^{\star}$ \\
BMI $\left(\mathrm{kg} / \mathrm{m}^{2}\right)$ & $33.56 \pm 1.83$ & $32.01 \pm 2.25$ & $33.46 \pm 2.1$ & 2.637 & $0.083^{*}$ \\
\hline
\end{tabular}

P: probability, ${ }^{\star}$ Non-significant as $\mathrm{P}>0.05$.

Table 2. Inter and intra group comparison among mean values of total cholesterol in the three groups measured pre- and post-treatment.

\begin{tabular}{llllll}
\hline Total cholesterol & Group A & Group B & Group C & F-value & P-value \\
\hline Pre-treatment & $231.93 \pm 26.88$ & $227.2 \pm 14.36$ & $221.46 \pm 13.6$ & 2.348 & $0.108^{\star}$ \\
Post-treatment & $188.33 \pm 26.39$ & $182 \pm 11.5$ & $213.06 \pm 12.54$ & 0.74 & $0.53^{\star}$ \\
\% of improvement & $18.8 \%$ & $19.8 \%$ & $3.79 \%$ & & \\
t-value & 19.39 & 16.92 & 3.84 & & \\
P-value & $0.001^{* *}$ & $0.002^{\star *}$ & $0.072^{\star}$ & & \\
\hline
\end{tabular}

P: probability ${ }^{\star}$ Non-significant as $\mathrm{P}>0.05$. ${ }^{*}$ Significant as $\mathrm{p}<0.05$. 
differences between the three groups for the pretreatment. While post treatment there were statistical significant differences between the three groups mean values as shown in Table 5 . Least significant difference (LSD) test between groups for lipid profile post-study Table 6 .

\section{Discussion}

The current research revealed meaningful differences and improvements occurred for lipid profile. However, the pre- sent study revealed that electro acupuncture had the upper hand than LLLT as obesity management protocol. Those who received acupuncture and aerobic training (walking on treadmill for $30 \mathrm{~min}$ ) twice weekly for 8 weeks (group B) had highly significant improvement in all the anthropometric measurements (total cholesterol, triglycerides, high density lipoproteins and low density lipoproteins) than those who received LLLT and aerobic training (walking on treadmill for $30 \mathrm{~min}$ ) twice weekly for 8 weeks (group A) those who

Table 3. Inter and intra group comparison among mean values of LDL in the three groups measured pre- and post-treatment.

\begin{tabular}{llllll}
\hline LDL & Group A & Group B & Group C & F-value & P-value \\
\hline Pre-treatment & $153.06 \pm 17.27$ & $146.2 \pm 12.23$ & $145.86 \pm 13.04$ & 2.956 & $0.087^{\star}$ \\
Post-treatment & $125.2 \pm 15.7$ & $104.8 \pm 12.65$ & $129.53 \pm 12.55$ & 0.74 & $0.53^{\star}$ \\
\% of improvement & $18.2 \%$ & $28.3 \%$ & $11.19 \%$ & & \\
t-value & 5.65 & 34.66 & 9.26 & & \\
P-value & $0.003^{\star *}$ & $0.001^{\star *}$ & $0.123^{*}$ & & \\
\hline
\end{tabular}

P: probability ${ }^{\star}$ Non-significant as $\mathrm{P}>0.05 .{ }^{*}$ Significant as $\mathrm{p}<0.05$.

Table 4. Inter and intra group comparison among mean values of HDL in the three groups measured pre- and post-treatment.

\begin{tabular}{llllll}
\hline HDL & Group A & Group B & Group C & F-value & P-value \\
\hline Pre-treatment & $37.53 \pm 4.18$ & $37.26 \pm 3.08$ & $38.86 \pm 2.8$ & 1.086 & $0.347^{\star}$ \\
Post-treatment & $49.33 \pm 3.28$ & $53.26 \pm 3.43$ & $40.25 \pm 2.7$ & 78.39 & $0.001^{\star *}$ \\
\%of improvement & $31.4 \%$ & $42.9 \%$ & $3.57 \%$ & & \\
t-value & -13.85 & -14.16 & -7.35 & & \\
P-value & $0.002^{\star *}$ & $0.001^{\star *}$ & $0.332^{\star}$ & & \\
\hline
\end{tabular}

P: probability ${ }^{\star}$ Non-significant as $\mathrm{P}>0.05 .{ }^{*}$ Significant as $\mathrm{p}<0.05$.

Table 5. Inter and intra group comparison among mean values of triglyceride in the three groups measured pre- and post-treatment.

\begin{tabular}{llllll}
\hline Triglyceride & Group A & Group B & Group C & F-value & P-value \\
\hline Pre-treatment & $156.73 \pm 4.94$ & $157.26 \pm 7.47$ & $154 \pm 6.15$ & 1.168 & $0.321^{\star}$ \\
Post-treatment & $122.6 \pm 6.32$ & $119.93 \pm 5.39$ & $137.66 \pm 6.13$ & 12.28 & $0.002^{\star *}$ \\
\%of improvement & $21.77 \%$ & $23.73 \%$ & $3.57 \%$ & & \\
t-value & 15.45 & 11.26 & -7.35 & & \\
P-value & $0.001^{\star *}$ & $0.001^{\star *}$ & $0.332^{\star}$ & & \\
\hline
\end{tabular}

$\mathrm{P}$ : probability ${ }^{\star}$ Non-significant as $\mathrm{P}>0.05 .{ }^{\star *}$ Significant as $\mathrm{p}<0.0$

Table 6. LSD test between groups for lipid profile post-study.

\begin{tabular}{lllllllll}
\hline Variable & \multicolumn{3}{c}{ Cholesterol } & \multicolumn{2}{c}{ LDL } & \multicolumn{2}{c}{ HDL } & \multicolumn{2}{c}{ Triglyceride } \\
\cline { 2 - 9 } & Mean difference & P-value & $\begin{array}{l}\text { Mean } \\
\text { difference }\end{array}$ & P-value & $\begin{array}{l}\text { Mean } \\
\text { difference }\end{array}$ & P-value & $\begin{array}{l}\text { Mean } \\
\text { difference }\end{array}$ & P-value \\
\hline Group A vs. group B & 6.33 & $0.044^{* *}$ & 20.4 & $0.001^{* *}$ & -3.93 & 0.001 & -17.33 & $0.001^{* *}$ \\
Group A vs. group C & -24.73 & $0.001^{* *}$ & -4.33 & $0.012^{* *}$ & 9.06 & $0.002^{* *}$ & -25.06 & $0.001^{* *}$ \\
Group B vs. group C & -31.06 & $0.001^{* *}$ & -24.73 & $0.001^{* *}$ & 13.01 & $0.001^{* *}$ & -17.73 & $0.002^{* *}$ \\
\hline
\end{tabular}

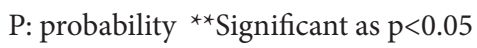


Mohamed et al, Physical Therapy and Rehabilitation 2018,

received aerobic training (walking on treadmill for $30 \mathrm{~min}$ ) twice weekly for 8 weeks (group C).

The results of electro acupuncture group (B) were consistent with Lee et al. [18] who reported that electro acupuncture lead to normalization of blood serum lipids, reduction of body mass and decrease fatty tissues content. They attributed the effect of acupuncture to its beneficial effect on hypothalamus pituitary axis. Adipose tissue in liver produce CAMP by the membranous enzyme adenylatecyclase that acts on ATP producing CAMP and liberating pyrophosphate; CAMP is involved in the activation of phosphorylase helping glycogenolysis and on lipase enzyme helping lipolysis $[19,20]$. While Zhou-hong [21] stated that acupuncture can provide good therapeutic effects for simple obesity, as after twenty sessions, the body weight, the serum total cholesterol (TC), the fasting triglyceride (TG) and low-density lipoprotein (LDL) were significantly changed. On the other hand, Acupuncture also increases the metabolic rate of the body and aids in burning more calories. It stimulates the release of hormones called endorphins that help to reduce the body fat. Whereas, this effect was not seen by exercise and diet [22].

Also, the results were confirmed by Zhang et al. [23] was demonstrating that acupuncture therapy significantly reduces $\mathrm{BMI}$ and abdominal adipose tissue by reducing abdominal visceral fat content without significant changes in body weight, waist circumference, hip circumference, WHR, abdominal subcutaneous adipose tissue. Thus, the use of acupuncture therapy to selectively target a reduction in abdominal visceral fat content should become more important and more popular in the future.

In accordance with current results, Chu et al. [19], found that acupuncture reduces triglycerides and total cholesterol levels in overweight and obese subjects, as acupuncture has a good regulatory effect on lipid metabolism and plasma cycling adenosine monophosphate(cAMP); that is involved in the activation of phosphorylase helping glycogenolysis and on lipase enzyme helping lipolysis. They attributed the effect of acupuncture to its beneficial effect on hypothalamus-pituitary axis.

Furthermore, Cabioglu and Ergene [24] stated that a significant decrease of triglyceride, total cholesterol, LDL-C but no changes in $\mathrm{HDL}-\mathrm{C}$ in acupuncture group when compared with controls. They suggested that these changes in lipid metabolism may be caused by increase in the serum beta endorphin levels. Moreover, Li and Wang [25] have reported significant changes in total cholesterol and LDL-c during acupuncture therapy when compared with control subjects.

The results of low LLLT agreed with Jackson and colleges which reported a significant decrease in the TC level after application of low-level laser therapy around abdomen for $20 \mathrm{~min}, 3$ sessions/week for 2 weeks [26].

One explanation of this improvement is that laser stimulates the lipid peroxidation and increases the superoxide production. Increased production of the reactive oxygen species breaks down lipids found in the cell membrane. Lipids and fatty material pass through transitory pores formed in the cell membrane and enter the interstitial space where the lymphatic system removes the fatty debris [27].

Also, the results were confirmed by Pinar Avci [28], who reported that low level laser therapy started being investigated as an adjuvant to liposuction, for noninvasive body contouring, reduction of cellulite, and improvement of blood lipid profile. LLLT may also aid autologous fat transfer procedures by enhancing the viability of adipocytes. However, the underlying mechanism of actions for such effects still seems to be unclear. It is important, therefore to understand the potential efficacy and proposed mechanism of actions of this new procedure for fat reduction.

Regarding traditional treatment in group (C), the results revealed significant improvement in the current group but less than group (A) and group (B) with $\mathrm{P}<0.05$.

In an attempt to explain the previous results Manson [13] reported that continuous physical activity from three to five sessions per week every session not less than 20 minutes helps to decrease lipid profile, blood pressure, osteoporosis and blood sugar level in both males and female's patients who had obesity associated high lipid profile. Physical activity has adverse proportional relationship with obesity and lipid profile.

Abnormal blood lipids have been firmly established as a modifiable risk factor for the development of CV disease. However medical practice in the area of lipid management is highly variable and has not been aggressively pursued for large number of patients that may be at risk.

\section{Conclusion}

There was a significant difference between electro acupuncture and low level laser therapy approaches in treating obesity. Findings of this study revealed the fact that treatment sessions of electro acupuncture were superior to low level laser therapy group in terms of significant improvement in cholesterol, LDL, HDL and TG levels in patients with obesity. So the best treatment intervention for obese patients with abnormal lipid profile can be obtained from electro acupuncture. This study was limited mainly to have long term follow up study. So, further research is needed, to include larger population, perform follow up study.

\section{Competing interests}

The authors declare that they have no competing interests.

Authors' contributions

\begin{tabular}{|l|c|c|c|}
\hline Authors' contributions & RAM & AMY & HKA \\
\hline Research concept and design & $\checkmark$ & $\checkmark$ & $\checkmark$ \\
\hline Collection and/or assembly of data & $\checkmark$ & $\checkmark$ & $\checkmark$ \\
\hline Data analysis and interpretation & $\checkmark$ & $\checkmark$ & $\checkmark$ \\
\hline Writing the article & $\checkmark$ & $\checkmark$ & $\checkmark$ \\
\hline Critical revision of the article & $\checkmark$ & $\checkmark$ & $\checkmark$ \\
\hline Final approval of article & $\checkmark$ & $\checkmark$ & $\checkmark$ \\
\hline Statistical analysis & -- & -- & -- \\
\hline
\end{tabular}


Mohamed et al, Physical Therapy and Rehabilitation 2018,

\section{Acknowledgements}

Many thanks, to all patients who participated

in this study for their co-operation.

\section{Publication history}

Editor: Mohammad H. Hadadzadeh, Wheeling Jesuit University, USA. Received: 21-Apr-2018 Final Revised: 20-Jun-2018

Accepted: 22-Jun-2018 Published: 04-Jul-2018

\section{References}

1. Abolfotouh MA, Soliman LA, Mansour E, Farghaly M and El-Dawaiaty AA. Central obesity among adults in Egypt: prevalence and associated morbidity. East Mediterr Health J. 2008; 14:57-68. | PubMed

2. Turkbey EB, McClelland RL, Kronmal RA, Burke GL, Bild DE, Tracy RP, Arai $A E$, Lima JA and Bluemke DA. The impact of obesity on the left ventricle: the Multi-Ethnic Study of Atherosclerosis (MESA). JACC CardiovasC Imaging. 2010; 3:266-74. | Article | PubMed Abstract | PubMed FullText

3. Encinosa WE, Bernard DM, Chen CC and Steiner CA. Healthcare utilization and outcomes after bariatric surgery. Med Care. 2006; 44:706-12. | Article | PubMed

4. Robins S. Management of lipid disorders. A basis and guide for therapeutic intervention. Boston, Massachusetts. 1997; 88-92.

5. Scanu AM. Lipoprotein disorders as related to atherosclerotic cardiovascular disease. Surg Clin North Am. 1995; 75:557-67. | Article | PubMed

6. Poli A, Marangoni F, Paoletti R, Mannarino E, Lupattelli G, Notarbartolo A, Aureli P, Bernini F, Cicero A, Gaddi A and Catapano A. Nonpharmacological control of plasma cholesterol levels. Nutr Metab Cardiovasc Dis. 2008; 18:S1-16. | Article | PubMed

7. Lacey JM, Tershakovec AM and Foster GD. Acupuncture for the treatment of obesity: a review of the evidence. Int J Obes Relat Metab Disord. 2003; 27:419-27. | Article | PubMed

8. Lee MS, Hwan Kim J, Lim HJ and Shin BC. Effects of abdominal electroacupuncture on parameters related to obesity in obese women: a pilot study. Complement Ther Clin Pract. 2006; 12:97-100. | Article | PubMed

9. Hsu $\mathrm{CH}$, Hwang $\mathrm{KC}$, Chao $\mathrm{CL}$, Chang $\mathrm{HH}$ and Chou P. Electroacupuncture in obese women: a randomized, controlled pilot study. $J$ Womens Health (Larchmt). 2005; 14:434-40. | Article | PubMed

10. Biernacki W and Peake MD. Acupuncture in treatment of stable asthma. Respir Med. 1998; 92:1143-5. I Pdf I PubMed

11. Lee H, Lee JY, Kim YJ, Kim S, Yin C, Khil JH, Kwon K, Choi SM and Park HJ. Acupuncture for symptom management of rheumatoid arthritis: a pilot study. Clin Rheumatol. 2008; 27:641-5. | Article | PubMed

12. Neira R, Arroyave J, Ramirez H, Ortiz CL, Solarte E, Sequeda F and Gutierrez MI. Fat liquefaction: effect of low-level laser energy on adipose tissue. Plast Reconstr Surg. 2002; 110:912-22. | Article | PubMed

13. Manson J, Hu F and Edwards J. A Respective Study of Walking As Compared With Vigorous Exercise in The Prevention of Coronary Heart Disease In Women. N. England. J. Med. 1991; 341:650-658.

14. Nigam PK. Serum Lipid Profile: Fasting or Non-fasting? Indian J Clin Biochem. 2011; 26:96-7. | Article | PubMed Abstract | PubMed FullText

15. Pal G, Dutta A, Mitra K, Grace MS, Romanczyk TB, Wu X, Chakrabarti K, Anders J, Gorman E, Waynant RW and Tata DB. Effect of low intensity laser interaction with human skin fibroblast cells using fiber-optic nano-probes. J Photochem Photobiol B. 2007; 86:252-61. | Article | PubMed

16. Abdi H, Zhao B, Darbandi M, Ghayour-Mobarhan M, Tavallaie S, Rahsepar AA, Parizadeh SM, Safariyan M, Nemati M, Mohammadi M, Abbasi-Parizad P, Darbandi S, Akhlaghi S and Ferns GA. The effects of body acupuncture on obesity: anthropometric parameters, lipid profile, and inflammatory and immunologic markers. ScientificWorldJournal. 2012; 2012:603539. | Article | PubMed Abstract | PubMed FullText

17. Norman JF, Hopkins E and Crapo E. Validity of the counting talk test in comparison with standard methods of estimating exercise intensity in young healthy adults. J Cardiopulm Rehabil Prev. 2008; 28:199-202. | Article I PubMed

18. Lee H, Kim SY, Park J, Kim YJ and Park HJ. Acupuncture for lowering blood pressure: systematic review and meta-analysis. Am J Hypertens. 2009; 22:122-8. | Article | PubMed

19. Chu NF, Stampfer MJ, Spiegelman D, Rifai N, Hotamisligil GS and Rimm EB. Dietary and lifestyle factors in relation to plasma leptin concentrations among normal weight and overweight men. Int J Obes Relat Metab Disord. 2001; 25:106-14. I PubMed

20. Sun F. [The antiobesity effect of acupuncture and it's influence on water and salt metabolism]. Zhen Ci Yan Jiu. 1996; 21:19-24. I PubMed

21. Wu ZH. Effects of the multiple needling with shallow insertion for simple obesity: a clinical observation on lipid metabolism and on the chest, waist and hip circumferences. J Tradit Chin Med. 2009; 29:179-81. | Pdf | PubMed

22. Tong J, Chen JX, Zhang ZQ, Liu CS, Pan Y, Zheng J and Yao H. [Clinical observation on simple obesity treated by acupuncture]. Zhongguo Zhen Jiu. 2011; 31:697-701. | PubMed

23. Zhang H, Peng Y, Liu Z, Li S, Lv Z, Tian L, Zhu J, Zhao X and Chen M. Effects of acupuncture therapy on abdominal fat and hepatic fat content in obese children: a magnetic resonance imaging and proton magnetic resonance spectroscopy study. J Altern Complement Med. 2011; 17:41320. | Article | PubMed

24. Cabioglu M.T and N Ergene. Electro acupuncture therapy for weight loss reduces serum total cholesterol, triglycerides and Idl cholesterol levels in obese women. The American Journal of Chinese Medicine. 2005; 33:525-533.

25. Li L and Wang ZY. [Clinical therapeutic effects of body acupuncture and ear acupuncture on juvenile simple obesity and effects on metabolism of blood lipids]. Zhongguo Zhen Jiu. 2006; 26:173-6. | PubMed

26. Jackson FR, Roche GC and Wisler K. Reduction in cholesterol and triglyceride serum levels following low-level laser irradiation: a non-controlled, nonrandomized pilot study. Am J Cosmet Surg. 2010; 27:177-84.

27. Olban M, Wachowicz B, Koter M and Bryszewska M. The biostimulatory effect of red laser irradiation on pig blood platelet function. Cell Biol Int. 1998; 22:245-8. | Article | PubMed

28. Avci P, Nyame TT, Gupta GK, Sadasivam M and Hamblin MR. Low-level laser therapy for fat layer reduction: a comprehensive review. Lasers Surg Med. 2013; 45:349-57. | Article | PubMed Abstract | PubMed FullText

\section{Citation:}

Mohamed RA, Yousef AM and Ata HK. Effect of electro acupuncture versus low level laser therapy on lipid profile in obesity. Phys Ther Rehabil. 2018; 5:9. http://dx.doi.org/10.7243/2055-2386-5-9 